Animal Health Research EL-Minia Lab.

\title{
ISOLATION OF CLOSTRIDIUM SPECIES FROM GEESE AND THEIR SUSCEPTIBILITY TO ANTIBACTERIAL AGENTS IN ASSIUT GOVERNORATE
}

(With 6 Tables)

By

\author{
A.A. ABDEL-RAHMAN; FATMA A. MOUSTAFA *; \\ MANAL H. THABT* and NEVEEN A. AHAMD \\ *Animal Health Research Assiut Lab.
}

(Received at 1/3/2007)

عزل ميكروبات الكلوستريديم من الإوز وتأثير المضادات الحيوية عليه

عبل الرحمن عبل المجي! عبل الرحمن ، فاطمة عبل المجيا مصطفى عاطي

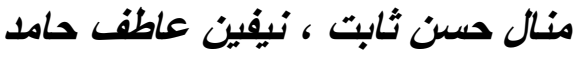

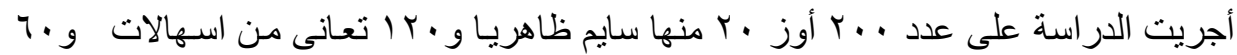

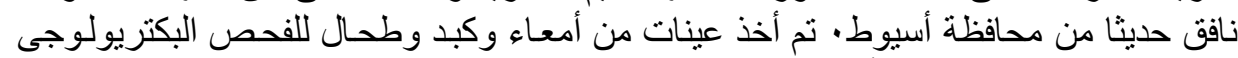

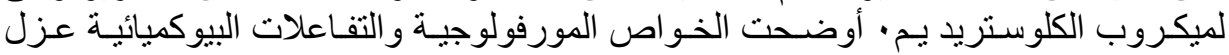

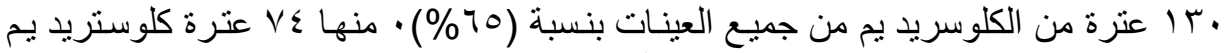

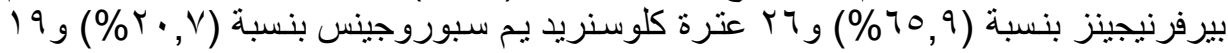

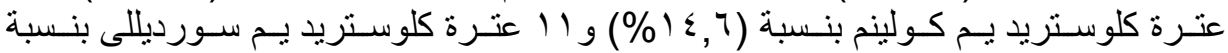

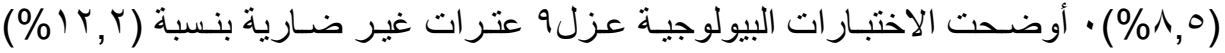

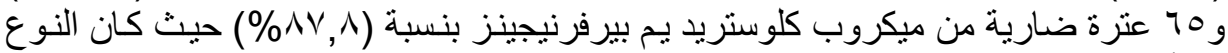

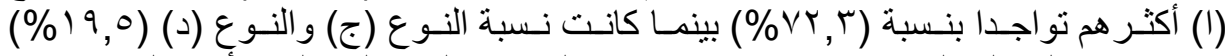

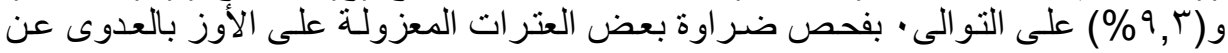

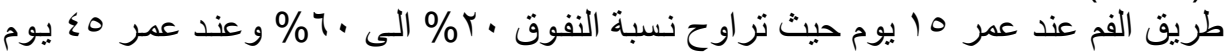

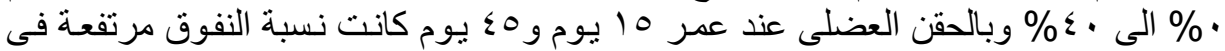

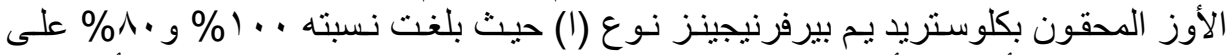

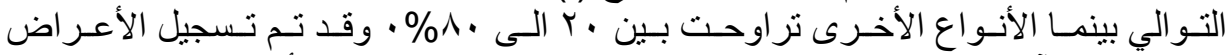

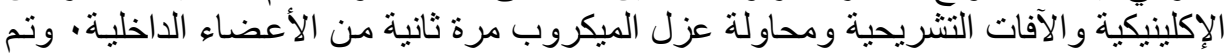

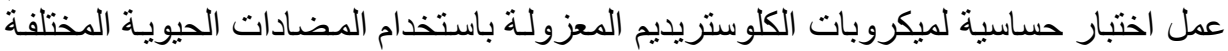
و التي ثبت فعاليتها لكل من البنسيللين وامبسللين والاموكسيللين و الكلور امنيفينوكول بينما كانت

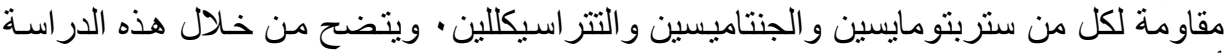

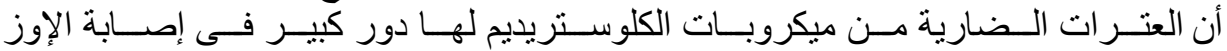
بالاضطر ابات المعوية وات النفوق مئن 


\section{SUMMARY}

A total of 200 geese (20 apparently healthy, 120 diarrhotic geese and 60 freshly dead) collected from privately owned at Assiut province were subjected to post-mortem and bacteriological examination for the prevalence of clostridia microorganisms in geese. There are variation in the prevalence rate of clostridium species isolated from apparently healthy geese which lower than of diarrhotic geese and freshly dead \& slaughtered. It was found $6(30 \%)$ in apparent healthy, $80(66.7 \%)$ in diseased geese, while was $44(73.3 \%)$ in dead geese According to morphological characters and biochemical reactions, 130 clostridium isolates were successfully isolated with an incidence of $65 \%$. The most important isolates was C. perfrigens with incidence of $74(56.9 \%)$ followed by C. sporogenes was 26 (20.7\%), C.colinum was 19 (14.6\%) and $\mathrm{C}$. sordelli was $11(8.5 \%)$. For the typing of $\mathrm{C}$ perfrigens isolated, type "A" was the most prevalent with incidence of (72.3\%) followed by type "C" with incidence of (18.5\%) and type "D: with incidence of $(9.3 \%)$. Tow age groups of geese (15 and 45 -day old) were used to test the pathogenicity of C.perfringens type "A", C. sporogenes, C.colinum and $\mathrm{C}$. sordelli. The mortality in geese at 15-day old through oral administration of C.perfringens type "A", C. sporogenes, C.colinum and C. sordelli were $60 \%, 40 \%, 20 \%$ and $20 \%$ respectively while were $100 \%, 80 \%, 60 \%$ and $20 \%$ respectively through $\mathrm{I} / \mathrm{M}$ inoculation and the mortality rate in geese at 45-day old through oral administration were $40 \%, 20 \%, 0.0 \%$ and $0.0 \%$ while were $80 \%, 40 \%, 20 \%$ and $0.0 \%$ respectively through $\mathrm{I} / \mathrm{M}$ inoculation. Sensitivity test of Clostridia strain isolates against some antibiotics in vitro showed that, Penicillin, Ampcillin, Amoxicillin, and Chloramephenical were highly sensitivity, while Lincomycin, Norfloxacin and Kanamycin were moderate and were resistant to Streptomycin, Gentamycin Tetracycline and Nalidixic acid.

Key words: Geese, clostridium

\section{INTRODUCTION}

Recently clostridium appeared to be of high significance among poultry all-over the world, and constitute one of the most important veterinary problems that face poultry industry in many countries including Egypt. The nature of its pathology in birds suggests a toxigenic mechanism, but testing of culture supernatant in laboratory animals has no effect. Necrotic enteritis first reported by Parish (1961) 
where it is a sporadic but considered as an important disease of boiler. Hussein (1972) isolated 225 clostridia isolates from 477 samples of intestinal tract from dead birds with incidence of (71\%) and apparently normal ones with incidence of $(24 \%)$. Out of them, 183 C.perfringens type A, 41 were type $\mathrm{C}$, one was type D while C.sporogenes was isolated from 3 cases. Ibrahim (1979) succeeded in isolation of clostridia from the small intestinal of diseased birds in higher incidence (38.1\%) than from normal chickens (19.3\%). Botulism is a sporadically occurring disease of both wild and domestic birds Smith (1977). Neumann (1983) recorded sever losses in wild ducks due to enterotoxaemia. Wobeser and Rainine (1987) found C.perifringens in large numbers in the intestines of geese suffering from a disease characterilized by severe necrotic enteritis. Necrotic enteritis is the disease accompanied with sever fatal diarrhea due to the production of exotoxins produced by clostridium microorganisms and mortality rates have ranged from 1 to $60 \%$ (Baba et al., 1992). Leighton et al. (1990) and Gardner (1992) mentioned that the role of clostridia organisms in duck were restricted to botulism caused by $\mathrm{C}$. botulinum type $\mathrm{C}$ toxin which causes high losses in water fowl all over the world. Songer (1996) reported that C. colinum is the aetiological agent of acute or chronic ulcerative enteritis of wild brides, quail and domestic fowl. Saad et al. (1997) isolated C.perifringens type A, C and D, C.sporogenes, C.sordelli and C.bifermenttans from both apparently and diseased duck. Abdel-El-Twab (2002) who isolated C.perifringens, C.sordelli and C.sporogenes from liver, intestine, kidney and spleen of apparently and diseased duck and geese.

The aim of this study through light on the incidence of clostridium species in geese and its sensitivity to some antibiotics.

\section{MATERIALS and METHODS}

\section{Materials:}

\section{1- Samples:}

A total of 200 geese at different ages (60 freshly dead diarrhoeic geese and 120 geese suffered from diarrhoea, addition 20 apparently healthy) were collected from different sources in Assiut Province to detect the prevalence and pathogenicity of Clostridium Spp. in diarrhoeic geese. Three samples were collocated (intestinal content, liver and spleen) from each bird.

\section{2- Culture media:}

a - Cooked meat medium "Mast DM 120" 
b- Neomycin blood agar medium (neomycin sulphate solution) was added to the media just before the additions of blood to make final concentration of $150 \mathrm{ug} / \mathrm{ml}$.

c- Thioglycollate broth medium (Oxoid, GM10)

d- Egg yolk agar media according to Levett (1991)

e- Medium for toxin production of C.perfrigens recommended by Roberts et al. (1970)

f- Antiserum "Burrough, Wellcome, Beckenham, London, England"

$\begin{array}{lllll}\text { RPO4 } & \text { Cl-perfringens } & \text { type A } & \mathrm{K} & 476810 \\ \text { RPO5 } & \text { Cl-perfringens } & \text { type B } & \mathrm{K} & 454010 \\ \text { RPO6 } & \text { Cl-perfringens } & \text { type C } & \mathrm{K} & 354610 \\ \text { RPO7 } & \text { Cl-perfringens } & \text { type D } & \mathrm{K} & 447710 \\ \text { RPO8 } & \text { Cl-perfringens } & \text { type E } & \mathrm{K} & 449710 \\ \text { RPO9 } & \text { Cl-perfringens } & \text { type control } & \mathrm{K} & 447910\end{array}$

g- Fermentable tests: according to (Levett, 1991).

h- Experimental laboratory animals:

\section{1- Albino guinea-pig:}

Albino guinea-pig with an average weight of 200-300gm were used in dermo-necrotic reaction for typing of isolated $\mathrm{C}$. perfringens The animals were kept under observation for 2 weeks before the beginning of inoculation.

\section{2-Swiss mice:}

Mice with an average weight (25-30gm) were used for the detection of toxin of C.perfringens. They were kept under observation for 2 weeks before they were inoculated.

\section{3- Experimental geese:}

Ninety geese (2-4 weeks-old) obtained from private flocks geese in EL-Minia Province were used in the pathogenicity and experimental studies.

\section{i- Antimicrobial sensitivity discs (Oxoid Laboratories):}

Antimicrobial sensitivity unidiscs produced by Oxoid LTD, London, England, including Ampcillin (10ug), Amoxicillin 25ug, Erythromycin 15ug, Neomycin (30ug), Norfloxacin (5ug), Tetracycline (30ug), Streptomycin (10ug), Chloramphenicol (30ug), Nalidixic acid (30ug), and Gentamycin (10ug) were used in this experiment j- Gas-pack anaerobic jar "BBL-814-12":

It was used for production of anaerobiosis by using disposable hydrogen-carbon dioxide bags with socket. (Baker platinum LTD, London). 


\section{Methods:}

\section{1- Isolation and identification of Clostridium spp.}

Liver, spleen and small pieces of the intestines with their contents from each sample were inoculated into two tubes of freshly sterile cooked meat broth. One tube was heated at in water bath at $60^{\circ} \mathrm{C}$ for 30 minutes to eliminate non-sporing organisms, whereas the second was left without heating. Both inoculated tubes were then incubated anaerobically at $37^{\circ} \mathrm{C}$ for 48 hours. A loopful from the heated tubes was inoculated on to $10 \%$ sheep blood agar plates while the unheated tubes were inoculated on to duplicated neomycin blood agar plates. The plates were incubated anaerobically at $37^{\circ} \mathrm{C}$ for $48 \mathrm{hr}$. The suspected colonies were examined and identified for microscopic appearance, culture character, motility, then transferred to cooked meat medium for other biochemical tests as described by Koneman et al. (1988) and Levett (1991).

2- Determination of typing and pathogenic C. Perfringens isolates: a- Nagler, ${ }^{\text {s }}$ reaction test: - (Hartwigk and Ghenitir, 1969)

In this test the plate egg yolk medium was soaked with few drop of antiserum of type "A", the second with antiserum of type "B" and the third acted as control and the same work was done on the other plate to type C, D, and E. After the dryness of antiserum, then added the centrifuged supernatant (3000 r.p.m.) cooked meat culture in ever part. The plates were incubated anaerboically at $37^{\circ} \mathrm{C}$ for $24 \mathrm{hr}$ and the results were recorded. An opalescence area appeared considered as positive cases

b- Neutralization test in mice: (Smith and Holdeman, 1968)

It was performed by adding $0.1 \mathrm{ml}$. of specific antisera $\mathrm{A}, \mathrm{B}, \mathrm{C}$, $\mathrm{D}$ and $\mathrm{E}$ of C.perfringes (Burrough, ${ }^{\mathrm{s}}$ Wellcome, Beckenham, London, England) to $3 \mathrm{ml}$. of the centrifuged supernatant (3000 r.p.m.) cooked meat culture. Supernatant culture of only type "D" was treated with $0.1 \%$ trypsin for 45 minutes at $37^{\circ} \mathrm{C}$. The mixture was left for 30 minutes at $37^{\circ} \mathrm{C}$ before its injection in mice. Its injection as $0.5 \mathrm{ml}$ into mice. The animal were put under observation for 3 days, the centrifuged supernatant (3000 r.p.m.) cooked meat broth culture without adding any antiserum was injected in mice and used as a control

3- Determination of the type of toxins in mixed culture by dermonectrotic test: (Stern and Batty, 1975)

Preparation of culture suspension:

A $48 \mathrm{hr}$. culture in cooked meat medium was prepared from the isolated Clostridia organisms. Gram stained smears made from the 
culture were examined microscopically to insure purity, then the pure culture was inoculated into flask contain peptone media and starch for production of alpha, beta and epislon toxins and incubated in water bath at $37^{\circ} \mathrm{C}$ for $8 \mathrm{hrs}$. The cultures suspensions were centrifuged for 30 minute at 3000 r.p.m. The clear supernatant fluid was then siphoned and divided into 5 portions, one portion was neutralized by alpha antitoxin, the second portion was neutralized by beta antitoxin, the third portion was neutralized with the type "C" antitoxin, the fourth portion was treated by trypsin and incubated at $37^{\circ} \mathrm{C}$ for one $\mathrm{hr}$, then neutralized by type "D" antitoxin while the fifth portion was left for the determination of toxin in the supernatant. The type of toxin was determined by dermonecrotic reaction recommend by inoculated Albino-guinea-pigs intradermally with $0.2 \mathrm{ml}$ of the untrypsinized toxin on the upper left and the trypsinized on the lower left, while the neutralized portions were inoculated on the right side at the same time, the guinea-pigs were kept under observation for 24-72 hr for any dermo-necritic reaction.

\section{4- Experimental laboratory animals:}

a)Pathogenicity to Swiss mice: Inoculated in tail vein with $0.3 \mathrm{ml}$ of centrifuged supernatant intestinal content of suspected C. perfrigens isolates. The animals were kept under observation for $72 \mathrm{hr}$.

\section{b) Pathogenicity to geese:}

Experimental infection design: The experiment was performed to study the pathogenicity of isolated microorganisms through oral administration and $\mathrm{I} / \mathrm{M}$ inoculation by $0.5 \mathrm{ml}\left(1.6 \times 10^{9}\right.$ organism $\left./ \mathrm{ml}\right)$ of $24 \mathrm{hr}$ cooked meat broth culture in geese at 15-day old and 45 day old. The plate count technique (Crucickshank et al., 1975) was used for determination of the viable count of cell per $\mathrm{ml}$ of suspension for each C-perfringens type "A", C- sporogenes C- colinum and C.sordelli. The $\mathrm{I} / \mathrm{M}$ application was done after injection of $0.5 \mathrm{ml}$ of $5 \%$ calcium chloride. The used technique was according to Al-Sheikhly and Truscott (1976). All inoculated geese were kept under observation for 14 days. Clinical signs and post mortem lesions of dead birds were recorded and trial for reisolation of inoculated organisms was conducted.

Ninety geese were used in this experimental. The birds were kept in cages and observed for a period a week. A random samples of 5 geese were slaughtered and exposed to post-mortem, parasitological and bacteriological examination, which proved their healthy status and free from diseases while, the other birds were classified into 16 groups Each group contain 5 geese. The last group was kept without inoculation as control Table (4) 


\section{5- Sensitivity test:}

The isolates were tested for sensitivity to different chemotherapeutic agents. One $\mathrm{ml}$ of $24 \mathrm{hr}$. broth cultures was spread on the surface of blood agar. Antibiotic sensitivity discs were placed on the surface seeded agar. Plates were incubated anaerobically at $37^{0} \mathrm{C}$ for $24 \mathrm{hr}$. The sensitivity was judged according to the diameter of clearance zone around the discs according to (Perelman et al., 1991).

\section{RESULTS}

Table 1: Morphological characters and biochemical reactions of different Clostridia isolates from examined geese

\begin{tabular}{|c|c|c|c|c|}
\hline \multirow[t]{2}{*}{$\begin{array}{l}\text { Characters and reactions } \\
\text { Of isolates }\end{array}$} & \multicolumn{4}{|c|}{ Type of Clostridia } \\
\hline & $\begin{array}{c}\text { C. perfringens } \\
\text { (74) }\end{array}$ & $\begin{array}{c}\text { C. sporogenes } \\
\text { (26) }\end{array}$ & $\begin{array}{c}\text { C- colinum } \\
\text { (19) }\end{array}$ & $\begin{array}{l}\text { C.sordelli } \\
\text { (11) }\end{array}$ \\
\hline \multicolumn{5}{|l|}{ Morphological character } \\
\hline Grams stain & + ve bacilli & +ve bacilli & +ve bacilli & +ve bacilli \\
\hline B.haemolysis & + & + & + & + \\
\hline Nagler effect & + & + & + & + \\
\hline Motility & - & + & + & + \\
\hline \multicolumn{5}{|l|}{ Biochemical reactions } \\
\hline Lecithinase & + & - & - & + \\
\hline Lipase & - & + & + & - \\
\hline Urease & $\mathrm{V}$ & - & - & + \\
\hline Indol & - & - & - & + \\
\hline $\mathrm{H}_{2} \mathrm{~S}$ & - & - & + & + \\
\hline Hydrolysis of gelatin & + & + & + & + \\
\hline \multicolumn{5}{|c|}{ Fermentation of carbohydrates } \\
\hline Lactose & + & - & - & - \\
\hline Sucrose & + & - & - & - \\
\hline Maltose & + & - & + & - \\
\hline Glucose & + & + & - & + \\
\hline
\end{tabular}

Table 2: Type and incidence of Clostridia organisms isolated from examined geese

\begin{tabular}{|c|c|c|c|c|c|c|c|c|c|c|c|}
\hline \multirow{2}{*}{$\begin{array}{c}\text { Status of } \\
\text { examined geese }\end{array}$} & \multirow{2}{*}{$\begin{array}{c}\text { Total No. of } \\
\text { examined } \\
\text { geese }\end{array}$} & \multicolumn{2}{|c|}{$\begin{array}{c}\text { Total No. of }+v e \\
\text { samples }\end{array}$} & \multicolumn{2}{|c|}{ C.perfringens } & \multicolumn{2}{|c|}{ C. sporogenes } & \multicolumn{2}{|c|}{ C. colinum } & \multicolumn{2}{|c|}{ C.sordelli } \\
\hline & & No. & $\%$ & No. & $\%$ & & & No. & $\%$ & No. & $\%$ \\
\hline Apparently healthy & 20 & 6 & 30.0 & 1 & 16.7 & 1 & 16.7 & 2 & 33.3 & 2 & 33.3 \\
\hline Diarrheic geese & 120 & 80 & 66.7 & 45 & 56.3 & 18 & 22.5 & 11 & 13.7 & 6 & 7.5 \\
\hline Freshly dead & 60 & 44 & 73.3 & 28 & 63.6 & 7 & 15.9 & 6 & 13.6 & 3 & 6.8 \\
\hline Total & 200 & 130 & 65.0 & 74 & 56.9 & 26 & 20.0 & 19 & 14.6 & 11 & 8.5 \\
\hline
\end{tabular}

*Percentage of positive samples calculated according to the total No. of examined samples

*Percentage of each isolates calculated according to the total No. of isolates 
Table 3: Incidence of Clostridia organisms isolated from different organs of examined geese.

\begin{tabular}{|l|c|c|c|c|c|c|c|c|}
\hline \multirow{2}{*}{ Source of sample } & \multirow{2}{*}{$\begin{array}{c}\text { Total No. of } \\
\text { examined } \\
\text { geese }\end{array}$} & \multirow{2}{*}{$\begin{array}{c}\text { Total No. } \\
\text { of +ve samples }\end{array}$} & \multicolumn{4}{|c|}{ Site of samples } \\
\cline { 4 - 10 } & & & \multicolumn{2}{|c|}{ Intestine } & \multicolumn{2}{|c|}{ Liver } & \multicolumn{2}{c|}{ spleen } \\
\cline { 5 - 10 } & & & No. & $\%$ & No. & $\%$ & No. & $\%$ \\
\hline Apparently healthy & 20 & 6 & 3 & 50.0 & 2 & 33.3 & 1 & 16.7 \\
\hline Diarrheic geese & 120 & 80 & 50 & 62.5 & 28 & 35.0 & 2 & 2.5 \\
\hline Freshly dead & 60 & 44 & 28 & 63.6 & 16 & 36.4 & 0 & 0.0 \\
\hline Total & 200 & 130 & 81 & 62.3 & 46 & 35.4 & 3 & 2.3 \\
\hline
\end{tabular}

$\%$ was calculated according to total No. of positive samples

Table 4: Incidence of non-toxigenic and toxigenic types of C.perfringens isolated from examined geese

\begin{tabular}{|c|c|c|c|c|c|c|c|c|c|c|c|}
\hline \multirow{3}{*}{ Health status } & \multirow{3}{*}{ 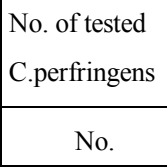 } & \multirow{2}{*}{\multicolumn{2}{|c|}{$\begin{array}{l}\text { Total No. of } \\
\text { non-toxigenic }\end{array}$}} & \multirow{2}{*}{\multicolumn{2}{|c|}{$\begin{array}{l}\text { Total No. of } \\
\text { toxigenic }\end{array}$}} & \multicolumn{6}{|c|}{ Type of toxigenic organism } \\
\hline & & & & & & \multicolumn{2}{|c|}{ A } & \multicolumn{2}{|c|}{$\mathrm{C}$} & \multicolumn{2}{|c|}{$\mathrm{D}$} \\
\hline & & No. & $\%$ & No. & $\%$ & No. & $\%$ & No. & $\%$ & No. & $\%$ \\
\hline Apparently healthy & 1 & 1 & 100 & 0 & 0.0 & 0 & 0 & 0 & 0 & 0 & 0 \\
\hline Diarrhotie geese & 45 & 6 & 13.3 & 39 & 86.7 & 28 & 71.8 & 7 & 17.9 & 4 & 10.3 \\
\hline Freshly dead & 28 & 2 & 7.1 & 26 & 92.9 & 19 & 73.1 & 5 & 19.2 & 2 & 7.7 \\
\hline Total & 74 & 9 & 12.2 & 65 & 87.8 & 47 & 72.3 & 12 & 18.5 & 6 & 9.3 \\
\hline
\end{tabular}

$\%$ of toxigenic and non-toxigenic isolates calculated according to No. of tested C.perfringens $\% *$ Type of toxigenic isolates calculated according to the total No. of toxigenic isolated

Table 5: Results of mortality rate of geese at 15 and 45 day-old. Due to oral administration and $\mathrm{I} / \mathrm{M}$ inoculation of different Clostridia organisms.

\begin{tabular}{|c|c|c|c|c|c|c|c|c|c|c|c|c|c|c|c|c|c|c|}
\hline \multirow{3}{*}{$\begin{array}{l}\text { Rout of } \\
\text { inoculation }\end{array}$} & \multirow{3}{*}{$\begin{array}{c}\text { No. of } \\
\text { geese } \\
\text { used }\end{array}$} & \multicolumn{8}{|c|}{15 day-old } & \multirow{3}{*}{$\begin{array}{c}\text { No. of } \\
\text { greese } \\
\text { used }\end{array}$} & \multicolumn{8}{|c|}{45 day-old } \\
\hline & & \multicolumn{2}{|c|}{$\begin{array}{c}\text { C.perfrigeen } \\
\text { type A. }\end{array}$} & \multicolumn{2}{|c|}{ C.sporoge } & \multicolumn{2}{|c|}{ C.colinum } & \multicolumn{2}{|c|}{ C.sordelli } & & \multicolumn{2}{|c|}{$\begin{array}{c}\text { C.perfrigeen } \\
\text { type A. }\end{array}$} & \multicolumn{2}{|c|}{$\begin{array}{l}\text { C. sporogenes } \\
\text { um }\end{array}$} & \multicolumn{2}{|c|}{ C.colinum } & \multicolumn{2}{|c|}{ C.sordelli } \\
\hline & & No. & $\%$ & No. & $\%$ & No. & $\%$ & No. & $\%$ & & No. & $\%$ & No. & $\%$ & No. & $\%$ & No. & $\%$ \\
\hline Oral & & 3 & 60 & 2 & 40 & 1 & 20 & 1 & 20 & & 2 & 40 & 1 & 20 & 0 & 0.0 & 0 & 0.0 \\
\hline $\mathrm{I} / \mathrm{M}$ & & 5 & 100 & 4 & 80 & 3 & 60 & 1 & 20 & & 4 & 80 & 2 & 40 & 1 & 20 & 0 & 0.0 \\
\hline
\end{tabular}


Table 6: In vitro sensitivity test of Clostridia species isolated to different chemotherapeutic agents

\begin{tabular}{|l|l|l|l|l|l|l|l|l|}
\hline \multirow{3}{*}{ Antibacterial agent } & \multicolumn{7}{|c|}{ Clostridia species } \\
\cline { 2 - 10 } & C.perfringens & \multicolumn{2}{|c|}{ C.sporogenes } & \multicolumn{2}{l|}{ C.colinum } & \multicolumn{2}{c|}{ C.sordelli } \\
\cline { 2 - 10 } & No. & $\%$ & No & $\%$ & No & $\%$ & No & $\%$ \\
\hline Ampcillin (10ug) & 4 & 80 & 4 & 80 & 3 & 60 & 4 & 80 \\
\hline Streptomycin (10ug) & 0 & 00 & 0 & 00 & 0.0 & 0.0 & 0 & 0.0 \\
\hline Kanamycin (30ug) & 2 & 40 & 3 & 60 & 3 & 60 & 2 & 40 \\
\hline Penicillin (1.5 I.U) & 5 & 100 & 4 & 80 & 5 & 100 & 4 & 80 \\
\hline Amoxicillin (10ug) & 4 & 80 & 4 & 80 & 4 & 80 & 3 & 60 \\
\hline Lincomycin (10ug) & 2 & 40 & 3 & 60 & 2 & 40 & 2 & 40 \\
\hline Norfloxacin (10ug) & 3 & 60 & 2 & 40 & 3 & 60 & 3 & 60 \\
\hline Chloramephenical (30ug) & 4 & 80 & 3 & 60 & 2 & 40 & 4 & 80 \\
\hline Tetracycline (30ug) & 1 & 20 & 1 & 20 & 0 & 0.0 & 1 & 20 \\
\hline Gentamycin (10ug) & 1 & 20 & 0 & 0.0 & 0 & 0.0 & 0 & 0.0 \\
\hline Nalidixic acid (30ug) & 0 & 0.0 & 0 & 0.0 & 0 & 0.0 & 0 & 0.0 \\
\hline
\end{tabular}

5 Strains for each clostridia species were tested from each

\section{DISCUSSIONS}

Anaerobic organisms including Clostridia species are considered now to be one of the most common and important of highly mortality in poultry including geese. Study of the prevalence of these organisms in geese represented a significant important.

Clinically, diseased geese were off food, ruffled feathers, depression and diarrhea. P.M examinations revealed that most lesions were found in small intestine and characterized by necrotic, ulcerative catarrhal to haemorrhagic inflammation, also found that congestion and enlargement of liver, kidney and spleen.

Results of this study according to the morphological characters, biochemical reactions and serological identifications of the recovered clostridia organisms from examined samples was Tabulated in Table (1). From the Table (2) it revealed to 130 Clostridia spp. was isolated from all examined samples with allover incidence of $(65.0 \%)$. Of these 6 (30\%) from apparent healthy, $80(66.7 \%)$ from diseased geese, while was $44(73.3 \%)$ from dead geese, these findings lower than obtained by El-Sisi and Hussein (1976) and Abd-El-Twab (2002) who isolated clostridia spp.from apparently health and diseased geese at 45-day old with incidence of $46.7 \%$ and $70 \%$ respectively. The incidence of Clostridia species isolated from intestine, liver and spleen for all examined samples was tabulated in Table (3) it showed that, the higher incidence of clostridia organisms were isolates from intestine was 
incidence of 81 (62.3\%), while was $46(35.4 \%)$ and $3(2.3 \%)$ from liver and spleen respectively from all examined samples. The prevalence rate of clostridia species from intestine, liver and spleen of apparent healthy were $3(50 \%), 2(33.3 \%)$ and $1(16.7 \%)$ respectively, while were $50(62.5 \%), 28(35 \%)$ and $2(2.5 \%)$ from diseased geese. These results are nearly agreement with the findings of Hafocre et al. (1986) and Abd-ElTwab (2002) who isolated clostridia species from intestinal tract, liver and spleen of apparent healthy with incidence of $36.7 \%, 20 \%$ and $0.0 \%$ respectively and $63.3 \%, 30 \%$ and $10 \%$ respectively from diseased geese. The most important isolates of clostridium organisms was C. perfrigens with incidence of $74(56.9 \%)$ followed by C. sporogenes was 26 $(20.7 \%)$, C.colinum was $19(14.6 \%)$ and C. sordelli was $11(8.5 \%)$. It is clear that C.perfringens was the highest incidence of the clostridia isolated from all examined samples. It was $1(16.7 \%)$ in apparent healthy, $45(56.3 \%)$ in diseased geese, while was $28(63.6 \%)$ in dead geese Table (2).Our results are in agreement with obtained by Wobeser and Rainnie (1987) found C.perfringens in large numbers in the intestines of geese suffering from a disease characterized by sever necrotic enteritis. From Table (4) it showed that, the incidence of toxingenic isolates of C.perfringens was $65(87.5 \%)$ while non- toxigenic was $9(12.2 \%)$ from all examined samples. The incidence of toxigenic isolates in diseased and dead geese were $86.7 \%$ and $92.9 \%$ while nontoxingenic isolates were $13.3 \%$ and $7.1 \%$ respectively. These findings are agreement with obtained by Abd-El-Twab (2002) who found the toxigenic isolates of C.perfringens which isolates from diseased geese was $93.8 \%$ while non-toxigenic isolates was $6.2 \%$.Concering typing of the toxigenic isolates of C.perfringens, it clear that C.perfringens type "A" was the main isolates with incidence of (72.3\%) followed by C.perfringens type " $\mathrm{C}$ " with incidence of (18.5\%) and type "D" with incidence of $(9.3 \%)$. These findings are nearly in agreement with the results obtained by Latinovic (1983) and Abd-El-Twab (2002) isolated C.perfringens type "A", type "C" and type "D" from diseased geese with incidence of $(73 \%),(6.7 \%)$ and $(20 \%)$ respectively. The experimental infection of recovered strains of C.perfringens type "A", C. sporogenes, C.colinum and $\mathrm{C}$. sordelli by oral administration and $\mathrm{I} / \mathrm{M}$ inoculation to geese at 15 day-old and 45 day-old it tabulated in Table (5) it revealed that, the mortality rate in geese at 15-day old with oral administration of C.perfringens type "A", C. sporogenes, C.colinum and C. sordelli were $60 \%, 40 \%, 20 \%$ and $20 \%$ respectively while were $100 \%, 80 \%, 60 \%$ and $20 \%$ respectively through $\mathrm{I} / \mathrm{M}$ inoculation and the mortality rate in geese 
at 45-day old through oral administration were $40 \%, 20 \%, 0.0 \%$ and $0.0 \%$ while were $80 \%, 40 \%, 20 \%$ and $0.0 \%$ respectively through $\mathrm{I} / \mathrm{M}$ inoculation, these findings nearly in agreement with the results obtained by Cowen et al. (1987), Kosovae et al. (1988) and Abd-El-Twab (2002) found that the mortality rate of geese at one-day old by oral infection with C.perfringens C. sordelli and C.sporogenes were $60 \%, 40 \%$ and $0.0 \%$ respectively while were $0.0 \%, 0.0 \%$ and $0.0 \%$ respectively at 45 day old, but $\mathrm{I} / \mathrm{M}$ inoculation at one day the mortality rate were $100 \%$, $60 \%$ and $0.0 \%$ while were $60 \%, 20 \%$ and $0.0 \%$ at 45 -day old. The high rate of mortality which reach to $80-100 \%$ through $\mathrm{I} / \mathrm{M}$ inoculation while was $0-40$ through oral infection, this is due to $\mathrm{I} / \mathrm{M}$ inoculation gives the organism suitable condition for anaerobiosis and secretes toxins which the main cause of death, while the oral infection needs certain predisposing factors to produce the disease through disfunction of intestine (Truscott and Al-Sheikhly, 1977)

\section{Results of sensitivity tests:}

In-vitro tests the proper antimicrobial agents against clostridia isolates, it illustrated in Table (6), it revealed that, Penicillin, Ampcillin, Amoxicillin, and Chloramephenical were highly sensitivity against clostridia isolates at rate of $80 \%$ to $100 \%$ while Lincomycin, Norfloxacin and Kanamycin were moderate sensitive, at rate of $40 \%$ to $60 \%$, on other hand clostridia isolates were resistant to Streptomycin, Gentamycin Tetracycline and Nalidixic acid. Our results findings are in agreement with other authors while disagreed with another due to extensive use of antibiotics as growth promoters and prophylactic agents for disease control in veterinary medicine has undoubtedly been responsible for large numbers of bacteria that have become resistant to different antibiotics. Secasiu (1995) tested the sensitivity of 453 strains of C.perfrigens isolated from fowel, turkeys, ducks and geese against 19 different antibiotics agents. He found that Penicillin, erythromycin, ampicillium, lincomycin were highly active and Furazolidone, Chloramphenicol, Tetracycline, bacitracin showed moderate activated, while were inactive to Streptomycin, Kanamycin and Sulfonamides. Abd-El-Twab (2002) found that C.perfringens, C.sporogenes and C. sordelli isolated from ducks and geese were highly sensitivity to chloramphenical, ampicillin, penicillin and kanamycin while least sensitivity to streptomycin, polymycin B, and sulphonamid.

From the abovementioned results, it can be concluded that, intestinal clostridia infections are a common problem among health of geese causing necrotic enteritis and high mortality so, the samples of 
diarroheatic geese must be subjected to the examination for anaerobic microorganisms in the routine work in the research laboratories and the treatment must be given after sensitivity test

\section{REFERENCES}

Abd-El-Twab, A.A. (2002): Prevalence of clostridial microorganisms in ducks and geese. J. Egyptian Vet. Med. Ass.62, No.1: 45-57. Al-Sheikhly, F. and Truscott, R.B. (1976): The interaction of Clostridium perfrigenes and its toxins in the production of necrotic enteritis in chickens. Avian Dis., 21 (2): 256-259.

Baba, E.; Fuller, A.L.; Gilbert, J.M. and Me.Dougald, L.R. (1992): Effect of Eburnetti infection and ditary zinc an experimental induction of necrotic enteritis in broiler chickens. Avian Dis. 36(1): 59-62.

Cowen, B.S.; Schwartz, L.D.; Vvilson, R.A. and Ambrus, S.I (1987): Experimentally induced necrotic enteritis in chickens Avian Dis.31 (4): 904-906.

Cruickshank, R.; Dugid, J.P.; Marmion, B.R. and Swain, R.H.A. (1975): Medical Microbiology. $2^{\text {nd }} V_{0} .12^{\text {th }}$ Ed. Livingstone, Edinburgh, London \& New York.

El-Sisi, M.A. and Hussein, A.Z. (1976): "Studies on poultry anaerobes in Egypt". Egypt J. Vet. Sci. 13 (1): 1-22.

Gardner, D.E. (1992): Botulism in New Zealand. Surveillance Wellington (2): 26-27.

Hafocre, C.L.; Frech, J.P.; Page, R.K. and Fletcher (1986): Subcutaneous of clostridium infection in broiler Avian Dis. 30 (3): 620-622.

Hartwigk, H. and Ghenitir, H. (1969): Demonstration of alpha toxin of C.welchii test discs. Zent. B1 Vet. Med. 16 (B) 226-276.

Hussein, A.Z. (1972): Studies on poultry anaerobes. Thesis, Presented to Faculty of Veterinary Medicine, Cairo University.

Ibrahim (1979): Anaerobic microflora of the small intestine of chickens. Thesis presented to Faculty of Veterinary Medicine, Assiut University.

Koneman, E.W.; Allen, S.D.; Dowell, V.R. and Sommers, H.M. (1988): Color Atlas and Text Book of Diagnostic Microbiology $2^{\text {nd }} E d$ J.B Lip. Co. New York and London. 
Kosovae, A.; Velhner, M.; Katrika, M. and Kamnena, V. (1988): Vaccination trial clostridia infection in geese. Peradarsiva Vet. Inst. Novi.Sad. Yugoslavia 23: 7/8) 20.

Latinovic, $V$. (1983): Study of characterizes of C.perfringens strains isolated from broilers with enteritis Veterinarian Yugoslavia 32 (2): 267-275.

Leighton, F.A.; Wobeser, G.; Cliplef, D.; Gillespie, M. and Pybus, M. (1990): Botulism in wild waterfowl: Albert, Manitoba and Saskatchewan. C. Vet. J., 31 (5): 395.

Levett, P.N. (1991): Anaerobic Microbiology (A practical approach) Oxford University Press. New York.

Neuman, D. (1983): Losses in wild ducks due to C.perfringens enterotoxaemia. Zeitschrift fur jagdwissenchaft 29 (2):126-129.

Parish, W.E. (1961): Necrotic enteritis in the fowl. J. Comp. Path. 71: 377-393.

Perelman, B.; Mints, S.; Zjut, M.; Kuttin, E. and Machny, S. (1991): An unusual Clostridium infection in broiler chickens Avian Pathology, 20: 475-480.

Roberts, R.S.; Guren, S. and Worrall, E.E. (1970): Studies on C.perfrigens J. Comp. Pathol., 80: 9-18.

Saad, A.E.; El-Bardisy, M.M. and El-Azzawy, H. (1997): Studies on some anaerobic infections in ducks. Benhia Vet. Med. J. Vol.8, No. (1) 26-44.

Secasiu, V. (1995): Chemosensitivity of Clostridium perfringens strains isolated from poultry. Revista Roman de Medicina Veterinary, 5 (1) 31-37.

Smith, L.DS. (1977): Botulism: The organism Its toxicity. The disease, Charles C. Thomas, springfiield.

Smith, L.D. and Holdeman, L.V. (1968): The pathogenic anaerobic bacteria IST Ed. Charles C. Thomas Publisher, U.S.A. PP. 201-205.

Songer, J.G. (1996): Clostridia enteric diseases of domestic animals Clinical Microbiology Reviews, 9 (2) 216-234.

Stern, M. and Batty, I. (1975): "Pathogenic Clostridia" 1 st edn, Butterworth, London. Boston.

Truscott, R.B. and Al-Sheikhly, F. (1977): Preproduction and treatment of necrotic enteritis in broilers. Am.J. Vet. Res. 38 (6) 857-861.

Wobeser, G. and Rainnie, D.J. (1987): Epizootic necrotic enteritis in wild geese J. Wildlife Dis., 23 (3): 376-385. 